\title{
Islam, Polygyny and Modern Contraceptive Use in Francophone sub- Saharan Africa
}

\author{
Margaret Farrell ${ }^{1 a}$, Adeline Masquelier ${ }^{b}$, Emily Tissot ${ }^{a}$, and Jane Bertrand ${ }^{a}$ \\ a Tulane University School of Public Health and Tropical Medicine \\ ${ }^{\mathrm{b}}$ Tulane University, Department of Anthropology
}

\begin{abstract}
Francophone sub-Saharan African countries have among the highest fertility rates and lowest modern contraceptive prevalence rates worldwide. This analysis is intended to identify the factors driving contraceptive prevalence in this population. In addition to testing the usual correlates, we have included three other variables potentially related to lower contraceptive use in the Francophone African context: being Muslim, being in a polygynous union, and participation in crucial decision-making processes.

We obtained descriptive statistics for II Francophone African countries with DHS data collected since 2000 for relevant variables. As expected, education, place of residence, age and number of children were significant for most countries in predicting modern contraceptive use. The final three factors yielded inconclusive results. The conventional correlates were by far the most predictive of MCPR, although women's participation deserves further analysis. These results dispel anecdotal evidence that being Muslim and in a polygynous union explain low CPR in this region.
\end{abstract}

Keywords: reproductive health, Demographic Health Surveys, modern contraceptive use, francophone sub-Saharan Africa, Islam

\section{Résumé}

Les pays d'Afrique sub-saharienne francophone comptent parmi les taux les plus élevés de fécondité et les plus bas de prévalence contraceptive moderne (TPCM) dans le monde. Cette analyse vise à identifier les facteurs conduisant à la prévalence contraceptive dans cette population. En plus de l'examen des corrélats habituels, nous avons inclus trois autres variables pouvant potentiellement être liées à une faible utilisation contraceptive dans le contexte africain francophone : être de religion musulmane, être en union polygame, et participer à des processus cruciaux de décision.

Nous avons obtenu des statistiques descriptives pour II pays d'Afrique francophone en utilisant les données des EDS collectées depuis 2000 pour les variables pertinentes. Sans surprise, l'éducation, lieu de résidence, âge et nombre d'enfants sont apparus comme des facteurs significatifs associés à l'utilisation contraceptive moderne pour la plupart des pays. Les trois derniers facteurs n'ont pas donné de résultats concluants. Les corrélats conventionnels sont de loin les plus déterminants du TPCM, bien que la participation des femmes mérite une analyse plus approfondie. Ces résultats dissipent toutes anecdotes selon lesquelles être musulmane et en union polygame expliquerait le faible TPC dans cette région

Mots clés: santé de la reproduction, Enquêtes Démographiques et de Santé (EDS), utilisation de la contraception moderne, Afrique francophone sub-saharienne, Islam

\footnotetext{
${ }^{1}$ Corresponding author: Margaret Farrell (mfarrellross@yahoo.com)
} 


\section{Introduction}

Francophone sub-Saharan African countries have some of the highest fertility rates and lowest contraceptive prevalence rates in the world. As of the latest Demographic Health Survey (DHS) available for each Francophone sub-Saharan African country, total fertility rates range from 4.2 births per woman (Gabon 2000) to 7.0 births per woman (Niger 2006). Modern contraceptive prevalence rates range from a low of $1.6 \%$ (Chad 2004) to a high of $17.7 \%$ (Burundi 2010). In response to the increasing concern at the international level regarding persistent high fertility in this region, as evidenced by the Ouagadougou Initiative, multiple parties - donors, governments, and NGOs - have renewed their interest in identifying the potential levers of change in relation to contraceptive use in this group of countries.

The objective of this study is to examine characteristics associated with modern contraceptive use in each of the Francophone sub-Saharan African countries, which have DHS data available. Worldwide, a well-known set of socio-economic factors education, urban/rural residence, number of living children, and age - are key determinants to contraceptive use (Bongaarts, 2006; Cleland, Ndugwa, \& Zulu, 20II; Kirk \& Pillet, 1998; Romaniuk, 20II). This analysis includes these same factors, but, also explores two less-researched variables as determinants of contraceptive use in this region: being Muslim and being part of a polygynous union.

Islam per se is not a deterrent to contraceptive use, as evidenced by Indonesia and Morocco - two predominantly Muslim countries that have modern contraceptive prevalence rates of $57 \%$ and $52 \%$, respectively. Indeed, it is well documented that Islamic law does not oppose the use of contraception (Roudi-Fahimi, 2004). However, the extremely low contraceptive prevalence rates throughout francophone West Africa and the widespread adherence to Islam has led to the perception that the two are related.

The adherence to religious norms that has led to an association between low contraceptive use and Islam is best described in Adjei Gyimah's statement "Religion is the 'alpha and omega' of African social institutions" where it can be seen that religion, or rather strict adherence to religious law, determines the culture and behavior of its people (Gyimah, 20I2). Specifically the law and socio-cultural factors that dictate attitudes toward modern contraception are often influenced by the social and religious norms dictated by Islam in francophone sub-Saharan African countries. As stated previously Islam does not oppose the use of contraception, however, through many facets Islam does encourage high fertility.

Traditional Islam supports large families for a variety of reasons. These reasons include financial gain, social elevation and religious purposes. In a patriarchal society where women typically assume the subservient gender role Islam puts women in a position where they must struggle to gain social capital. In cases such as Niger, women are not seen as man's equal. They are not allowed to own land, inherit money, or marry without permission (Cooper, 2010) although this is changing (young people increasingly are choosing their partners, etc.). Although it varies in degree, this situation is not uncommon in other Francophone sub-Saharan African countries. Young women of these countries elevate themselves from these "low status" through piety, pleasing their husbands, and achieving reproductively through childbirth (Johnson-Hanks, 2006).

It is not always easy to identify the extent to which Islam is responsible for encouraging people to have large families. The idea that health, prosperity, and success are tied to fertility predates the advent of Islam in many regions of West Africa. Today many still believe that large families are better able to confront economic adversity than smaller ones because they draw income from a variety of sources.

The Quran itself makes a plea for the elevation of women through motherhood. Many passages are dedicated to honoring a mother's nobility and kindness (Noble Quran 46:15). These references to a woman's nobility are exclusive to her position as a mother in the household. People say that the prophet Muhammad also declared to his followers that on Judgment Day he wanted to have more followers than any other prophet. Which also suggests an emphasis on large families and the importance of reproduction in Islam. Although some Muslims are religious in name only, it is important to note the importance that religion plays on society and social norms. Generally even an irreligious Muslim will publicly abide by the standards and regulations set by the general Muslim community.

In addition to the religious views of child-birth among Muslims, Muslim women have many economic reasons for wanting to have many children. They provide a free source of labor for the family, especially boys who are able to do physical labor (Wall 1988). Similarly, girls are desirable for their domestic value but not seen as future income earn- 
ers and therefore are not as important as their male counterparts. Producing children is also one of the only ways for a woman to solidify her financial security in her old age. Her sons have the ability to carry on the family line and claim inheritance. In her old age these sons will assume the full responsibility of caring for their aging mothers and act as the primary income earners. Throughout Francophone Africa, a critical distinction is made between contraceptive practices aimed at limiting the number of children a woman gives birth to and birth spacing. Although some young educated women speak of wanting only so many children, women who use contraception (as well as health practitioners) typically speak not of limiting births but of spacing them to ensure that all children survive beyond infancy. It is an important distinction to African Muslims who say that children come from God and that only God can decide how many children a couple will give birth to. From this perspective, limiting the number of one's children amounts to "playing God." Additionally, women typically need their husbands' authorization to use birth control. Men, for whom power and masculinity are bound up in their ability to produce progeny, are often reluctant to limit the number of children they can have. When contraception is available from petty vendors who hawk a variety of medicines (as opposed to being available in pharmacies and health centers), women are more likely to use it because they do not need their husbands' permission.

Polygyny, described as a marriage in which one husband has multiple wives, is also a potential determinant of high fertility and low contraceptive use. Ezeh (1997) has cited the role that polygyny plays in determining reproductive behavior, including preferences for ideal family size, desire for more children, and current contraceptive use.

VanDeWall (200I) describes the heightened importance of children when the woman enters into a polygynous marriage because of co-wife competition. Wives in polygynous marriages must compete for their husband's attention and resources. It is not uncommon that these marriages are rife with conflict between wives and the children of each wife, who must also compete for resources (Romaniuk 20II). Children born into polygynous marriages often live in controversy with their half brothers and sisters often defending their mother from other wives and children as well as competing for resources.

Women living in polygynous marriages often share many characteristics of Muslim women discussed in this paper; often the two attributes coin- cide. Polygynous marriages are patriarchal with the husband serving as the principal decision maker and guardian over his wives. Women in these situations have little autonomy and like Muslim women elevate themselves in the household by providing sons and daughters to their husband. Wives who bear a large number of children are able to compete with the other wives for the husband's resources and affections. These wives often earn a side income through small business ventures that they undertake. Children often provide the free labor necessary for them to sustain these businesses.

Most importantly these children will be raised to become income generators for their mothers. She will depend on them to care for her as her husband takes on other wives and financial responsibilities. They become her security into old age as the fierce competition of polygyny pushes her outside of her husband's favor. Women in a polygynous union and women who are Muslim share many of the same attributes for low contraceptive use and a desire for large families. However, polygyny heightens the need for many children because of the fierce co-wife competition found in polygynous marriages.

This paper examines the relative importance of four "conventional" determinants of modern contraceptive use - education, urban-rural residence, number of living children, and age - as well as two factors hypothesized to influence CPR in francophone sub-Saharan Africa: religion and polygyny.

\section{Methods}

The data for this analysis of characteristics associated with modern contraceptive use come from the Demographic and Health Surveys (DHS) in francophone countries of Western and Central Africa. We downloaded these publicly available datasets from www.measuredhs.com. This analysis includes II Francophone countries in West and Central Africa that had DHS data collected during or after the year 2000 , including the variable "religion." (We eliminated one other country -Mauritania [2000] - because data were not collected on religion.)

All analyses of the factors associated with modern contraceptive use were limited to married women of reproductive age (MWRA). The independent factors included variables available from the DHS datasets in their original form, as well as those recoded for purposes of this analysis (e.g., women's age was grouped as 15-24, 25-34, 35+). Similarly, some variables with existing categories were collapsed due to small sample sizes or to improve clarity of interpretation (e.g., respondents with second- 
ary education or a higher level of education were grouped into "secondary or higher.") For the variable "desire for more children," the responses "wants more children within two years, wants more after two years, and wants more children but unsure of timing" were all grouped into a single "wants more children" category.

The outcome of interest, modern contraceptive use, was defined to include oral contraceptives, IUD, diaphragm, injections, implants, male/female condoms, female/male sterilization, and foam/jelly. Users of folkloric/traditional methods (including lactational amenorrhea [LAM], periodic abstinence/rhythm, withdrawal, and "other" methods) or no contraceptive method were categorized as nonusers of modern contraception. Although in some countries the DHS has classified LAM as a modern method, it has been included as a traditional method across all countries in this analysis. A study of LAM use based on DHS data found that only $26 \%$ of selfreported LAM users were using the method correctly, indicating poor quality of self-reported data concerning LAM use (Fabic \& Choi, 2013). Therefore, self-reported users of the LAM method likely have a much lower user-effectiveness rate than the $98 \%$ efficacy rate of LAM when used correctly. For this reason, LAM was categorized as a traditional method for all countries included in this analysis. A single logistic regression model was created for each of the II countries, using modern contraceptive use as the dependent variable and six socio-economic factors as explanatory variables. The same set of variables was included in each of the logistic regression models in order to compare directionality of the effect as well as significance for each factor across countries.

\section{Results}

Table I presents the socio-demographic characteristics of married women of reproductive age in each country, based on the most recent DHS for each country. These data reflect widely known trends: the majority of women in Francophone West and Central Africa have low levels of education, tend to live in rural areas, and desire to continue childbearing.

Table 2 presents descriptive data for the II countries on the two factors of key interest in this analysis: religion (percent Muslim) and type of marital union (polygynous vs. monogamous); in addition, it shows the bivariate relationships between these two factors and place of residence (urban/rural).
The percentage of MWRA who were Muslim ranged widely, from $1.3 \%$ in DRC to $98.2 \%$ in Niger. The percentage of women reporting to be in a polygynous union varied from $6.2 \%$ in Burundi to $52.3 \%$ in Guinea. Polygynous unions were more common in rural than in urban areas for both Muslims (in 9 of II countries) and for non-Muslims (in all I I countries).

We then conducted a multivariate analysis to test the relative importance of the widely recognized determinants of contraceptive use (education, age, urban/rural residence, and number of living children) among MWRA in comparison to the two variables thought to play a special role in this region: religion (Muslim or not) and type of marital union (polygynous or not). We created a separate logistic regression model for each of the II countries, using modern contraceptive use as the outcome.

As expected, education level, urban/rural residence, age and number of living children were significant for most countries in predicting modern contraceptive use (see Table 3). Specifically, MWRA with a secondary or higher education were much more likely to use modern contraception than those with no education. Also, with the exception of Burundi, married women in urban areas were significantly more likely to use modern contraception than those living in rural areas. All countries except DRC showed the commonly found curvilinear relationship between age and contraceptive use, with the highest use among women 25-34. With only a few exceptions, the number of living children was a statistically significant predictor of modern contraceptive use, with a greater number of living children being associated with a higher likelihood of modern contraceptive use. The pattern is less clear with desire for more children, although where significant results were found, the trend was in the expected direction: those wanting more children had a lower likelihood of using modern contraceptives.

The main variables of interest in this analysis were religion and polygyny. In multivariate analyses that controlled for the factors cited above, polygyny was significant in only 3 of the II countries (Benin, Burkina Faso and Senegal) but in the opposite direction of what was anticipated. That is, in these three countries MWRA in a polygynous union were more likely than those in a monogamous union to use a modern contraceptive method. Religion was significant in only 3 countries (Burundi, Cameroon, and Senegal), but the direction of the relationship was inconsistent. In two countries (Cameroon and Senegal) Muslim MWRA were more likely than nonMuslims to use a modern contraceptive method, 
while in Burundi, the opposite was true. Results for Senegal may be spurious as $96.6 \%$ of married women are Muslim in that country; however, this does not explain the unexpected result in Cameroon, where only $24.8 \%$ of married women are Muslim.

In short, this analysis did not confirm the hypothesis that being Muslim and being in a polygynous union contribute to explaining the low modern contraceptive prevalence in francophone countries in West and Central Africa.

\section{Discussion}

As with any analysis which utilizes secondary data as its primary source of information, this analysis does have its limitations. Because of the standardized nature of the DHS questionnaire as well as the cost of administration among other reasons, this questionnaire is unable to capture all correlates of modern contraceptive use in Francophone sub-Saharan Africa. For example, this analysis did not capture male attitudes toward contraceptive use or measure of the social status of women (relative to local norms). This data, if gathered, would greatly contribute to the discussion on modern contraceptive use by polygynist and Muslims because both of these indicators demonstrate women's autonomy in the region. Women's autonomy is then directly linked to choice of modern contraception. It is suggested that future research include a gender empowerment variable that provides this additional information on women's autonomy.

This analysis also had no process for determining how strongly the respondent identifies with being Muslim, which may be even more important that the depth of religious belief. In primarily homogenous societies it is common that the people who follow Islamic law and social norms do so in order to participate in the society. Therefore, the obligation of certain behaviors and practices is placed on the society as a whole. Women who do not hold deep religious conventions or identify strongly with the religion often follow Islamic teachings in terms of family planning practices because it is the social norm.

One possible explanation for the lack of evidence supporting Islam and polygyny as factors of modern contraceptive use is the high degree of correlation between the known indicators of contraceptive use and these two factors. Indicators of modern contraceptive use such as education and urban-rural residence already correspond very closely with Muslim and non-Muslim as well polygyny. In a multivariate analysis that includes education and urban-rural resi- dence, Islam and polygyny provide little additional explanatory power.

The programmatic implications of the findings in this analysis are that programs must continue to work within the constraints of known sociodemographic determinants of contraceptive use, but also attempt to affect prevalence through other mechanisms, such as increasing access to contraception, improving quality of services, and influencing social norms related to family size.

\section{Authors Contributions:}

Margaret Farrell was responsible for the conception and design of the analysis, statistical analysis and interpretation of the results, literature review and writing of the article.

Adeline Masquelier was responsible for literature review and anthropological content of the article Emily Tissot was responsible for literature review. Jane Bertrand was responsible for the conception and design of the analysis and writing of the article.

\section{Acknowledgements:}

The analysis was supported under grant \#OPPI0I707 from the Bill and Melinda Gates Foundation and does not necessarily reflect positions or policies of the Foundation. The authors thank Dr. Jean-Pierre Guengant for reviewing an earlier draft of the manuscript.

\section{References}

Bongaarts, J. (2006). The causes of stalling fertility transitions. Studies in Family Planning, 37(1), I16.

Cleland, J. G., Ndugwa, R. P., \& Zulu, E. M. (20II). Family planning in sub-Saharan Africa: Progress or stagnation? Bulletin of the World Health Organization, 89(2), I37-I43. doi: I0.247I/BLT.10.077925

Cooper, B. (2010).

Secular states, Muslim law and Islamic religious culture: Gender implications of legal struggles in hybrid legal systems in contemporary West Africa. Droit Et Cultures, 59, 97-I 20.

Cooper, B. (1997). Marriage in Maradi: Gender and Culture in a Hausa Society in Niger, 1900-1989. Portsmouth, $\mathrm{NH}$ : Heinemann.

Ezeh, A. C. (1997). Polygyny and reproductive behavior in sub-Saharan Africa: A contextual analysis. Demography, 34(3), 355-368.

Fabic, M. S., \& Choi, Y. (20I3). Assessing the quality of data regarding use of the lactational amenor- 
rhea method. Stud Fam Plann, 44(2), 205-22I. doi: 10.1 I I I/j. 1728-4465.2013.00353.x

Gyimah, S., Adjei, J., \& Takyi, B. (20I2). Religion, Contraception, and Method Choice of Married Women in Ghana, Journal of Religion and Health, 5I(4), I359-I374.

Kirk, D., \& Pillet, B. (1998). Fertility levels, trends, and differentials in sub-Saharan Africa in the 1980s and 1990s. Studies in Family Planning, 29(I), I-22.

Johnson-Hanks, J., (2006). Uncertain honor; modern motherhood in an African crisis. Chicago: University of Chicago Press.

Kirk, D., \& Pillet, B. (1998). Fertility levels, trends, and differentials in sub-Saharan Africa in the 1980s and 1990s'. Studies in Family Planning, 29(I), I-22.
Obeng Gyimah, S., Adjei, J., \& Takyi, B.,. (20I2). Religion, contraception, and method choice of married women in Ghana. J Religion Health, 51, |359-1374. doi: 10. 1007/s 10943-0 I |-9478-4.

Romaniuk, A. (201 I). Persistence of high fertility in tropical Africa: The case of the Democratic Republic of the Congo. Population and Development Review, 37(I), I-28.

Roudi-Fahimi., F. (2004). Islam and family planning. Population Reference Bureau, (Mena Policy Brief), I-8.

VanDeWalle, E., Renne, E., (Ed.). (200I). Regulating menstration. Chicago: University of Chicago Press.

Wall., L. (1988). Hausa medicine; illness and wellbeing in a West African culture. London: Duke University Press. 
Table I. Socio-demographic Profile of Married Women of Reproductive Age in II Francophone African Countries

\begin{tabular}{|c|c|c|c|c|c|c|c|c|c|c|c|}
\hline \multirow[b]{2}{*}{ Country } & \multirow[b]{2}{*}{$\begin{array}{l}\text { Last } \\
\text { DHS }\end{array}$} & \multicolumn{3}{|c|}{ Education } & \multirow{2}{*}{$\begin{array}{l}\text { Residence } \\
\text { \% Urban }\end{array}$} & \multicolumn{3}{|c|}{ Age Group } & \multirow{2}{*}{$\begin{array}{c}\text { \# Living } \\
\text { Children } \\
\\
\text { Mean } \\
\end{array}$} & \multirow{2}{*}{$\begin{array}{c}\begin{array}{c}\text { Desire for } \\
\text { More Chil- } \\
\text { dren }\end{array} \\
\begin{array}{c}\text { Want no } \\
\text { more }\end{array} \\
\end{array}$} & \multirow{2}{*}{$\begin{array}{c}\text { Contraceptive } \\
\text { Use }\end{array}$} \\
\hline & & $\%$ None & $\%$ Primary & $\begin{array}{c}\text { \% Secondary } \\
\text { or higher }\end{array}$ & & $\begin{array}{c}\% \\
15-24 \\
\end{array}$ & $\begin{array}{c}\% \\
25-34 \\
\end{array}$ & $\% 35+$ & & & \\
\hline Benin & 2006 & 73.5 & 17.8 & 8.7 & 36.4 & 21.5 & 44.6 & 33.9 & 3.31 & 28.4 & 5.9 \\
\hline Burkina & 2010 & 82.0 & 11.1 & 6.9 & 21.2 & 27.5 & 38.5 & 34.0 & 3.31 & 24.3 & 14.9 \\
\hline Burundi & 2010 & 54.1 & 39.6 & 6.4 & 8.5 & 24.1 & 39.9 & 36.0 & 3.39 & 33.0 & 17.7 \\
\hline Cameroon & 2011 & 27.3 & 37.5 & 35.2 & 47.3 & 28.6 & 38.2 & 33.2 & 3.17 & 27.3 & 14.1 \\
\hline Chad & 2004 & 78.5 & 17.2 & 4.2 & 18.4 & 31.7 & 37.8 & 30.5 & 3.42 & 9.0 & 1.6 \\
\hline DR-Congo & 2007 & 24.0 & 41.5 & 34.5 & 40.3 & 29.3 & 37.6 & 33.1 & 3.29 & 20.5 & 5.8 \\
\hline Gabon & 2000 & 7.9 & 38.7 & 53.4 & 76.3 & 28.4 & 38.5 & 33.2 & 3.12 & 23.3 & 11.8 \\
\hline Guinea & 2005 & 85.3 & 8.0 & 6.6 & 26.1 & 23.4 & 35.5 & 41.0 & 3.15 & 23.1 & 4.0 \\
\hline Mali & 2006 & 82.1 & 10.3 & 7.5 & 30.8 & 32.1 & 35.6 & 32.4 & 3.14 & 20.2 & 6.3 \\
\hline Niger & 2006 & 87.6 & 9.0 & 3.4 & 15.0 & 30.7 & 37.2 & 32.1 & 3.35 & 9.0 & 5.0 \\
\hline Senegal & 2010 & 70.8 & 19.8 & 9.4 & 41.1 & 26.7 & 38.2 & 35.1 & 3.15 & 22.0 & 11.9 \\
\hline
\end{tabular}


Table 2. Married women of reproductive age by country: percent Muslim and percent in polygynous unions in urban and rural areas

\begin{tabular}{|c|c|c|c|c|c|c|c|c|c|}
\hline \multirow[b]{3}{*}{ Country } & \multirow[b]{3}{*}{ Last DHS } & \multirow[b]{3}{*}{$\begin{array}{l}\% \text { Women } \\
\text { that are Mus- } \\
\quad \lim \end{array}$} & \multirow[b]{3}{*}{$\begin{array}{l}\text { \% Women in Po- } \\
\text { lygynous Union }\end{array}$} & \multicolumn{6}{|c|}{$\%$ Women in polygynous unions } \\
\hline & & & & \multicolumn{3}{|c|}{ of Muslims } & \multicolumn{3}{|c|}{ of non-Muslims } \\
\hline & & & & Urban & Rural & Total & Urban & Rural & Total \\
\hline Benin & 2006 & 23.2 & 43.0 & 43.0 & 52.5 & 48.9 & 33.1 & 45.7 & 41.2 \\
\hline Burkina & 2010 & 63.8 & 42.3 & 26.8 & 50.8 & 45.7 & 10.5 & 43.0 & 36.2 \\
\hline Burundi & 2010 & 2.3 & 6.2 & 13.9 & 25.9 & 20.6 & 3.8 & 6.1 & 5.9 \\
\hline Cameroon & 2011 & 24.8 & 26.9 & 37.0 & 45.0 & 42.1 & 13.1 & 29.8 & 21.7 \\
\hline Chad & 2004 & 57.5 & 39.1 & 36.9 & 41.3 & 40.4 & 31.0 & 38.5 & 37.3 \\
\hline DR-Congo & 2007 & 1.3 & 22.8 & 38.9 & 27.8 & 34.1 & 17.4 & 26.1 & 22.7 \\
\hline Gabon & 2000 & 8.1 & 21.3 & 23.2 & 24.0 & 23.2 & 19.3 & 26.6 & 21.1 \\
\hline Guinea & 2005 & 86.8 & 52.3 & 42.8 & 59.1 & 54.7 & 25.7 & 38.8 & 36.9 \\
\hline Mali & 2006 & 92.0 & 39.7 & 27.7 & 45.5 & 39.9 & 21.5 & 40.6 & 37.9 \\
\hline Niger & 2006 & 98.2 & 35.8 & 36.5 & 35.5 & 35.7 & 21.5 & 42.5 & 40.1 \\
\hline Senegal & 2010 & 96.6 & 34.6 & 28.5 & 39.8 & 35.2 & 8.4 & 25.7 & 17.1 \\
\hline
\end{tabular}


Table 3. Logistic regression: factors related to modern contraceptive use in II Francophone West and Central African countries

\begin{tabular}{|c|c|c|c|c|c|c|c|c|c|c|c|c|c|c|c|}
\hline \multirow[b]{3}{*}{ Country } & \multirow{3}{*}{$\begin{array}{l}\text { Last } \\
\text { DHS }\end{array}$} & \multicolumn{14}{|c|}{ Model parameters } \\
\hline & & & & \multicolumn{4}{|c|}{$\begin{array}{c}\text { Education Level } \\
\text { (reference }=\text { No education) }\end{array}$} & \multicolumn{2}{|c|}{$\begin{array}{c}\text { Residence } \\
\text { (reference = Rural) }\end{array}$} & \multicolumn{4}{|c|}{$\begin{array}{c}\text { Age group } \\
\text { (reference }=15-24)\end{array}$} & \multirow{2}{*}{$\begin{array}{l}\text { Number } \\
\text { of living } \\
\text { children }\end{array}$} & \\
\hline & & Intercept & & $\begin{array}{l}\text { Secondary } \\
\text { or higher }\end{array}$ & & Primary & & Urban & & $25-34$ & & $35+$ & & & \\
\hline Benin & 2006 & -2.93 & **** & 0.67 & **** & 0.02 & NS & 0.20 & **** & 0.08 & NS & -0.05 & NS & 0.10 & **** \\
\hline Burkina & 2010 & -4.49 & **** & 3.39 & **** & 2.75 & **** & 0.44 & **** & 0.18 & **** & -0.25 & *** & 0.14 & *** \\
\hline Burundi & 2010 & -1.73 & **** & 0.55 & **** & -0.13 & * & 0.13 & NS & 0.23 & **** & -0.52 & **** & 0.15 & **** \\
\hline Cameroon & 2011 & -2.78 & **** & 0.96 & **** & 0.24 & **⿻丷木 & 0.27 & **** & 0.07 & NS & -0.21 & **⿻丷木 & 0.07 & $* *$ \\
\hline Chad & 2004 & -4.34 & **** & 1.26 & **** & -0.14 & NS & 1.27 & **** & 0.24 & NS & -0.51 & NS & 0.18 & * \\
\hline DR-Congo & 2007 & -3.24 & **** & 0.53 & **** & -0.04 & NS & 0.49 &  & -0.03 & NS & -0.03 & NS & -0.02 & NS \\
\hline Gabon & 2000 & -3.09 & **** & 0.78 & **** & 0.07 & NS & 0.52 & **** & 0.07 & NS & -0.43 & *** & 0.08 & NS \\
\hline Guinea & 2005 & -2.59 & **** & 0.85 & **** & -0.16 & NS & 0.62 & **** & 0.13 & NS & -0.16 & NS & 0.03 & NS \\
\hline Mali & 2006 & -2.57 & **** & 0.74 & **** & 0.10 & NS & 0.51 & **** & 0.19 & *** & -0.52 & **** & 0.16 & **** \\
\hline Niger & 2006 & -2.62 & **** & 0.67 & **** & 0.13 & NS & 0.83 & **** & 0.31 & **** & -0.50 & **** & 0.14 & $* * *$ \\
\hline Senegal & 2010 & -2.45 & **** & 0.47 & **** & 0.20 & *** & 0.51 & **** & 0.23 & **** & -0.12 & NS & 0.19 & **** \\
\hline
\end{tabular}

Table 3 (cont'd). Logistic regression: factors related to modern contraceptive use in II Francophone West and Central African countries 


\begin{tabular}{|c|c|c|c|c|c|c|c|c|c|}
\hline \multirow[b]{3}{*}{ Country } & \multirow{3}{*}{$\begin{array}{l}\text { Last } \\
\text { DHS }\end{array}$} & \multicolumn{8}{|c|}{ Model parameters } \\
\hline & & \multicolumn{4}{|c|}{$\begin{array}{c}\text { Desire for more children } \\
\text { (reference }=\text { Wants no more) }\end{array}$} & \multicolumn{2}{|c|}{$\begin{array}{c}\text { Marriage } \\
\text { (reference }=\text { Monogamous union) }\end{array}$} & \multicolumn{2}{|c|}{$\begin{array}{c}\text { Religion } \\
\text { (reference }=\text { non-Muslim) }\end{array}$} \\
\hline & & Wants more & & Undecided & & Polygynous & & Muslim & \\
\hline Benin & 2006 & -0.04 & NS & -0.34 & NS & 0.12 & *** & 0 & NS \\
\hline Burkina & 2010 & 0.1 & NS & -0.53 & *** & 0.12 & **** & 0.06 & NS \\
\hline Burundi & 2010 & 0.26 & $*$ & -0.73 & *** & -0.08 & NS & -0.28 & *** \\
\hline Cameroon & 2011 & 0.04 & NS & -0.28 & NS & -0.01 & NS & 0.34 & **** \\
\hline Chad & 2004 & -0.19 & NS & -0.18 & NS & -0.22 & NS & 0.29 & NS \\
\hline DR-Congo & 2007 & -0.39 & $*$ & -0.06 & NS & -0.02 & NS & 0.27 & NS \\
\hline Gabon & 2000 & -0.19 & NS & 0 & NS & 0.03 & NS & -0.01 & NS \\
\hline Guinea & 2005 & -0.6 & $* * *$ & 0.15 & NS & 0.08 & NS & 0.17 & NS \\
\hline Mali & 2006 & -0.26 & * & -0.27 & NS & -0.05 & NS & 0.11 & NS \\
\hline Niger & 2006 & -0.27 & NS & -0.06 & NS & -0.02 & NS & -0.15 & NS \\
\hline Senegal & 2010 & 0.15 & NS & -0.56 & $*$ & 0.21 & ***** & 0.29 & *** \\
\hline
\end{tabular}

